\title{
Política social e Direitos Humanos sob o jugo imperial dos Estados Unidos
}

\section{Social policies and human rights under the imperial rule of the United States}

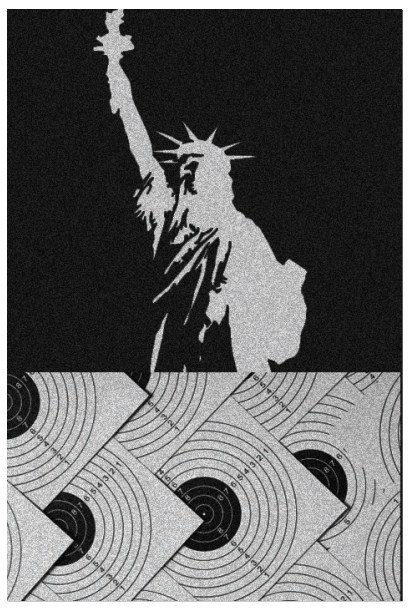

\author{
Potyara Amazoneida P. Pereira* \\ Marcos César Alves Siqueira**
}

Resumo: Este ensaio versa sobre ataques aos direitos humanos e à política social, apesar da força discursiva que, contemporaneamente, ambos passaram a ter. Tais agressões se acentuaram com o fim da bipolaridade entre Estados Unidos (EUA) e ex-União Soviética (URSS), no final dos anos 1980, com a autodissolução da URSS, em 1991, e com a transformação dos EUA em superpotência mundial. Contudo, ao se transformar, os Estados Unidos, em alvo de atos terroristas, supostamente praticados por países pobres, a pobreza foi criminalizada e transformada em inimigo número um. Isso explica o desmonte dos direitos humanos, notadamente os sociais, e das políticas publicas que visam concretizá-los.

Palavras-chave: Política social. Direitos humanos. Imperialismo. Criminalização da pobreza.

Abstract: This article deals with the attacks to human rights and to social policies, in spite of their discursive power contemporarily. Such attacks were stressed by the end of the bipolarity between the United States (USA) and the ex-Soviet Union (USSR) at the end of the 1980's, by the USSR's

* Professora titular e emérita do Departamento de Serviço Social da Universidade de Brasília (UnB)/ Distrito Federal, Brasil. Vice-coordenadora do Núcleo de Estudos e Pesquisas em Política Social (Neppos), do Centro de Estudos Avançados Multidisciplinares (Ceam) da UnB; pesquisadora do CNPq e líder do Grupo de Estudos Político-Sociais (Politiza) do Programa de Pós-graduação em Política Social da UnB, registrado no Diretório dos Grupos de Pesquisas do CNPq.E-mail: potyamaz@gmail.com.

** Pesquisador do Núcleo de Estudos e Pesquisas em Política Social (Neppos/Ceam/UnB); membro do Grupo de Estudos Politiza do Programa de Pós-Graduação em Política Social (PPGPS) da UnB; mestre e doutorando em política social pelo PPGPS/UnB.E-mail: mcasiqueira@gmail.com. 
self-dissolution in 1991, and by the transformation of the USA into a world superpower. However, when the USA became target of terrorist attacks, supposedly committed by poor countries, poverty was criminalized and became enemy number one. That fact explains the disassembling of the human rights, mainly the social ones, and of the public policies which aim at implementing them.

Keywords: Social policy. Human rights. Imperialism. Criminalization of poverty.

\section{Introdução}

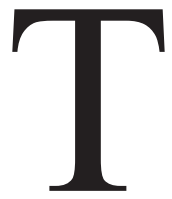

ratar da temática conjugada da política social e dos direitos humanos implica reconhecer que tal política e tais direitos estão seriamente ameaçados, apesar da força discursiva que passaram a ter, desde o final dos anos 1980, com o término da Guerra Fria e do socialismo real.

Com efeito, a partir dos anos 1990, generalizou-se a ideia de que, com o fim da bipolaridade entre Estados Unidos (EUA) e União Soviética (URSS), e com a autodissolução desta, o mundo viveria em paz, sob a hegemonia da democracia liberal norte-americana. No entanto, foi justamente a América do Norte, defensora das liberdades individuais, que, nas palavras de Loïc Wacquant (2006), se transformou na primeira sociedade de "insegurança avançada" da história - uma sociedade que "promoveu a insegurança como princípio de organização da vida coletiva e forma de regulação das trocas socioeconômicas e dos comportamentos individuais" (p. 23).

Para tanto, o modo de ser e de fazer negócios norte-americanos foram estratégica e sistematicamente exportados, tanto para a periferia do capitalismo, da qual o Brasil faz parte, quanto para outros países e regiões capitalistas centrais. Nestes, é emblemático o caso da Europa que, na sequência da Segunda Guerra Mundial, se tornou dependente da ajuda estadunidense para sair dos escombros produzidos pelo conflito bélico e para compensar a perda de suas antigas e rentáveis colônias (Judt, 2008; Sader, 2003). Consequentemente, a partir daí, os Estados Unidos foram se tornando uma potência dominante, não só no continente europeu, mas em todo o mundo.

Esse quadro indica, ademais, que não se pode falar em ameaça aos direitos humanos e à política social de forma abstrata ou pontual; mas, pelo contrário, exige situar tal ameaça no contexto mais amplo das concretas relações de poder 
econômico, político, cultural, militar e midiático, no qual, desde o fim do segundo pós-guerra, os Estados Unidos vêm assumindo liderança inconteste.

Por outro lado, é fato empírico que, na ausência de seu mais poderoso oponente - a URSS ${ }^{1}$ —, os Estados Unidos “elegeram” um novo adversário: a pobreza; ou melhor: os perigos que a pobreza interna e externa ao seu território passaram a representar sob a forma de terrorismo, narcotráfico, guerrilhas, corrupção, migração ilegal, inveja, fundamentalismo religioso, resistência ao consumismo e incapacidade de aceitação do American way of life (Sader, 2003). Indícios desse fato não faltam.

Em 2002, em discurso na Conferência Internacional sobre Financiamento ao Desenvolvimento, na cidade mexicana de Monterrey, o então presidente George W. Bush declarou, em meio à emotividade pós-11 de Setembro do ano anterior, que

lutamos contra a pobreza porque a esperança é uma resposta ao terrorismo. Nós lutamos contra a pobreza porque a oportunidade é um direito e uma dignidade humana fundamental. Nós lutamos contra a pobreza porque a fé o exige, e a consciência o pede. E nós lutamos contra a pobreza com a convicção cada vez maior de que progressos importantes estão ao nosso alcance. (Departamento de Estado dos Estados Unidos, 2014)

Tal declaração reiterava, sem dúvida alguma, a nova postura maniqueísta dos Estados Unidos de encarar pobreza como contraparte de "condutas desviantes" (terrorismo, principalmente), como se ambos fossem faces de uma mesma moeda, cujo combate constituiria uma cruzada de fé ou um ato de generosidade de uma nação predestinada a ser a guardiã do planeta.

Contudo, na contramão do discurso, os Estados Unidos, como diz Wacquant (2006), apresentam taxas de criminalidade mais altas do que em outras nações

1. Depois de 1945, isto é, com o término da Segunda Guerra Mundial, os Estados Unidos da América “estabeleceram com a União Soviética - a outra superpotência da época — uma espécie de condomínio mundial caracterizado por uma furiosa rivalidade que será designada de Guerra Fria" (Ramonet, 1998, p. 43). Entretanto, com a "implosão da União Soviética”, em 1991, os Estados Unidos se viram “colocados em uma situação que nenhuma potência conheceu" no século XIX. Desde então, institui-se no mundo uma hegemonia única e exclusiva, fato considerado sem igual na história da humanidade (Idem). 
desenvolvidas e índices alarmantes de homicídios e encarceramentos. Isso, sem falar da sua superioridade na corrida armamentista mundial que, depois da Segunda Grande Guerra e da Guerra Fria que lhe sucedeu, aparentemente não teria por que continuar existindo. Diz-se aparentemente porque se sabe que a indústria armamentista e o estímulo a guerras é uma das formas de o capitalismo se reproduzir, ampliar e dissipar riquezas (Mészáros, 2009) - coisa que nenhum país do globo exercitou tão bem como os Estados Unidos. Que o digam as contínuas vitórias econômicas e políticas desse país no plano internacional, incluindo a recuperação da Europa mencionada, as quais tiveram como leitmotiv "a intensificação do comércio de armas" (Ramonet, 1998, p. 45).

Com efeito, desde 1945, os Estados Unidos vêm se envolvendo, direta ou indiretamente, em centenas de conflitos armados, movidos, em última instância, por interesses econômicos. Dentre os mais importantes e escancarados (seja por meio da atuação militar efetiva, ajuda logística, financiamentos diretos e indiretos, seja mediante lucrativas vendas de armamentos) ${ }^{2}$ pode-se destacar: Irã (1953); Guatemala (1954 e 1993); Baía dos Porcos — Cuba (1961); República Dominicana (1961); Brasil ${ }^{3}$ (1964); Iraque (1968, 1990 e 2003); Chile (1973); Afeganistão (1979 e 2001); Turquia (1980); Nicarágua (1981); Granada (1983); Panamá (1989); Bósnia-Herzegovina (1995); Iugoslávia (1999); Venezuela (2002); Líbia (2011), entre muitos outros ${ }^{4}$ (Chomsky, 1999; Mitchell e Schoeffel, 2005).

Além dessas intervenções, outras dezenas foram e ainda são realizadas com vistas a monitorar os passos de diversas nações. Segundo reportagem de

2. Como no famoso escândalo Irã-Contras, em que os Estados Unidos venderam armas ao Irã (em meio a um embargo internacional sobre a venda de armas para esse país), sendo que parte dos lucros foi utilizada para financiar o movimento anticomunista dos "Contras", na Nicarágua, a partir de 1979.

3. Que por muito pouco não foi invadido pelos Estados Unidos, como parte da chamada Operação Brother Sam.

4. Como os demais países da América do Sul, a saber: Argentina, Bolívia, Paraguai e Uruguai, que (com o Chile e o Brasil) integraram um movimento orquestrado entre todos os regimes militares autoritários deste continente, denominado Operação Condor. Esta iniciativa, chancelada pelos Estados Unidos, tinha como objetivo neutralizar todas as investidas socialistas, comunistas e demais organizações não afinadas com os regimes autoritários dos respectivos países. Justamente por ser uma manobra articulada no âmbito de toda a América do Sul, criou-se uma rede de informações, investigações e repressão interligada, cooperativamente, entre todos os seus membros. Essa rede facilitou a ocorrência de atrocidades, como assassinatos, torturas, sequestros e extradições ilegais. 
2013 do site canadense Global Research, os Estados Unidos, até aquele momento, interviram (direta ou indiretamente), em nada menos do que 74 países, em especial na África e no Oriente Médio, sendo que o atual presidente Barack Obama ampliou o espectro dessas atuações em relação ao seu antecessor, George W. Bush. Isso confirma o intento autodeclarado dos Estados Unidos de se tornar o grande império global. ${ }^{5}$

Entretanto, em todas as intervenções estadunidenses a questão dos direitos humanos e da política social foi matematicamente calculada. Em vista disso, tal questão não constituía um assunto da alçada doméstica dos países monitorados, mas algo cujo enfrentamento devia passar pelo crivo dos Estados Unidos, de suas forças armadas, de sua inteligência, de seus políticos e investidores, bem como de órgãos multilaterais sintonizados com a sua ideologia. Tome-se como exemplo a ajuda financeira concedida pelo Fundo Monetário Internacional (FMI), Banco Mundial e suas instituições afiliadas a muitos desses países: tal ajuda era acompanhada de condicionalidades que impunham medidas de ajuste nas economias dos países tomadores de empréstimos (os chamados ajustes estruturais), as quais contribuíram para o surgimento de nações com potente capacidade agroexportadora, mas, ao mesmo tempo, com uma população pobre e desfalcada de direitos sociais.

\section{Violência institucionalizada contra os direitos humanos a partir do domínio imperial estadunidense}

Efetivamente, a postura imperial norte-americana tem estimulado ataques frontais aos direitos humanos, proclamados no século XVIII, na esteira das conquistas iluministas que combatiam as arbitrariedades do Estado absolutista e elegiam o indivíduo como "sujeito da liberdade e da criação" (Touraine, apud Acanda, 2006, p. 52); e responde, consideravelmente, pela disseminação inter-

5. Isso pôde ser verificado após os escândalos da rede clandestina de vigilância eletrônica internacional (liderada pelos Estados Unidos), denunciada pelo ex-técnico da Agência Nacional de Segurança (NSA), Edward Snowden, em 2013. 
nacional desses ataques e pela prática da violência cotidiana no seio de cada nação, incluindo os Estados Unidos.

Como observa David Harvey (2005, p. 40), “[esse] país tem um histórico de intolerância [interna] que nega seu apego à sua Constituição e ao regime de direito". Porém, é em relação ao mundo externo que a sua intolerância se exacerba com falsas justificativas.

Suas constantes intervenções bélicas em nações menores, identificadas como inimigas, tem-se feito a pretexto de repressão preventiva, que passa por cima de acordos internacionais e da soberania dessas nações. Seu tradicional apoio e patrocínio a golpes de Estado onde lhe der na telha, já lhe rendeu a pecha de "maior 'Estado irresponsável' da terra" (Harvey, 2005, p. 40). Suas numerosas e diversificadas formas de interdição econômica e política em países e instituições internacionais, como os "embargos comerciais ao Iraque e a Cuba", e ingerências favoráveis à adoção de políticas de austeridade junto ao FMI, têm sido tão deletérias quanto a "força física" (Idem). Contemporaneamente, a exclusiva preponderância do seu poder imperialista tornou-se uma realidade inusitada porque tal poder, conforme Ramonet (1998), não mais se mede, como acontecia nos impérios anteriores, pela influência geográfica e militar, mas "resulta essencialmente da supremacia no controle das redes econômicas, dos fluxos financeiros, das inovações tecnológicas, das trocas comerciais, das extensões e projeções (materiais e imateriais) de toda espécie" (p. 45).

Daí o seu magnetismo e força em um momento histórico de relativa consolidação de fronteiras geográficas.

De fato, desde a Guerra Fria, nenhuma nação capitalista sente-se imune ao poder de influência norte-americano, seja em que área for. Caso emblemático é o da "indústria do imaginário" que, como nenhum outro país, os Estados Unidos souberam capitalizar tão bem. Trata-se, em linhas gerais, da indústria de filmes, músicas, modas, bebidas e comidas, dentre outros produtos culturais qualitativamente ruins, embora não sem reações de alguns países, como a França. ${ }^{6}$ No entanto, tem-se que admitir que o seu poder de penetração e controle

6. Foi na França, segundo Judt (2008, p. 232), que os planos de expansão internacional da Coca-Cola "provocaram turbulências públicas. Quando Le Monde revelou que a companhia havia estabelecido a meta 
de mentes e preferências é inegável. Para ficar apenas com um produto, vale lembrar que, na Europa,

entre 1947 e 1949, a Coca-Cola Company abriu fábricas na Holanda, Bélgica, em Luxemburgo, na Suíça e Itália. Cinco anos após ter sido criada, a Alemanha Ocidental contava com 96 dessas fábricas e se tornara o maior mercado fora dos Estados Unidos. (Judt, 2008, p. 232)

Confiante em seu poderio universal, alicerçado em uma economia "flamejante", no dizer de Ramonet (1998), os Estados Unidos radicalizaram as suas idiossincrasias contra o seu mais novo inimigo: as subclasses (underclasses) perigosas, internas e externas. Em 1990 o governo de George W. Bush criou uma nova doutrina de segurança nacional (ou de guerra), em represália à invasão do Kuwait pelas tropas do Iraque de Saddam Hussein; e, em 2001, essa doutrina foi consolidada após os ataques terroristas às torres gêmeas de Nova York (Sader, 2003). Tal consolidação instituiu o que foi denominado de guerra infinita contra o terrorismo, a qual passou a ser conhecida como guerra assimétrica, devido à imprevisibilidade dos atos de terror (Sader, 2003, p. 31). E, a partir de então, os pobres, tidos como empecilhos e potenciais agressores a uma sociedade pautada pelo ideário da acumulação incessante de lucro e riqueza, graças à mecânica exploração do trabalho humano, deveriam sofrer o seguinte enquadramento: trabalhar para prover o seu autossustento ou ser criminalizados. Esta é a lição ou a ética capitalista da "responsabilidade", atualmente em voga, a qual expressa, segundo Dean (2007), o triunfo do princípio da obrigação do indivíduo pelo seu próprio bem-estar sobre o direito de ser assistido; ou o que pode ser descrito como retração da responsabilidade pública para com as necessidades dos cidadãos.

\footnotetext{
de 240 milhões de garrafas a serem vendidas, em 1950, houve objeções veementes - incentivadas, mas não orquestradas, pelos comunistas, que se limitavam a advertir que os serviços de distribuição da Coca-Cola funcionariam também como rede de espionagem norte-americana". Porém, cabe informar que, a despeito das resistências francesas à "coca-colonização", havia, na Europa, de modo geral, noções comuns (à direita e à esquerda) a respeito das evidentes ambições imperialistas por trás da expansão cultural de seus produtos, que iam dos filmes de bang-bang a refrigerantes.
} 


\section{Incremento do processo de criminalização da pobreza e de afrontas aos direitos humanos}

Como era previsível, o crescimento de crimes cometidos contra segmentos sociais desprotegidos, para além das fronteiras dos Estados Unidos, não se fez tardar. Porém, parafraseando Dean (2007), considera-se que a proliferação da violência expressa nesse crescimento, atingindo países periféricos como o Brasil, se deu de forma incremental e não abrupta. Além disso, a expansão progressiva do capitalismo em busca de lucros crescentes não criou novas fórmulas de destruição da natureza e da vida humana, mas renovou e intensificou as de sempre.

Dados veiculados pelo Relatório Anual da Anistia Internacional, de 2009, revelam que, no bojo da crise sistêmica e estrutural do capital, ressaltam a seguinte realidade: em 2008, 81 países restringiram a liberdade de expressão em seu território; 78\% das execuções ocorreram em países do G-20; 27 países negaram asilo a pessoas que poderiam morrer se voltassem para sua terra de origem; e, em $47 \%$ dos países do G-20, pessoas sofreram julgamentos injustos. Ainda de acordo com o referido Relatório, o mundo está passando por uma grave e preocupante crise de direitos humanos, que não tem explicação em si mesma, mas faz parte de uma situação calamitosa de desigualdade e insegurança sociais prestes a explodir.

As agressões aos direitos humanos são também praticadas por setores da sociedade contra cidadãos (nativos ou estrangeiros), e entre concidadãos, motivados por preconceitos de classe; ódios raciais, religiosos, ideológicos; intolerâncias a opções sexuais; recrudescimento de nacionalismos, xenofobias, separatismos; moralismos, superexploração do trabalho e criminalização da pobreza (Alves, 2005).

Vários estudos, como os de Wacquant, indicam a prevalência contemporânea de um "Estado penal" que, rejeitando a ética da proteção social, crimina-

7. O Grupo dos 20 é formado por representantes governamentais, geralmente ministros das Finanças, e banqueiros das dezenove maiores economias mundiais, mais a União Europeia (UE). Esta, por sua vez, é formada por 28 países que se uniram para realizar parcerias econômicas e políticas. 
liza e pune os pobres, os diferentes, os desiguais, os estranhos, que não conseguiram se colocar acima ou à parte do vasto sistema de insegurança social capitalista. Nesse sistema, pontua Wacquant, referindo-se à América do Norte, só escapa "a alta nobreza das empresas e do Estado" (2006, p. 24), o que revela o paroxismo a que chegou a divisão de classes numa época em que muitos acreditam não mais existir classes sociais.

Efetivamente, sob a égide do Estado penal, as políticas de enfrentamento à pobreza e à desigualdade social tornaram-se antissociais (Pereira-Pereira, 2009). E, como tal, desincumbiram-se de quaisquer responsabilidades que possam caracterizar deveres do Estado e direitos dos cidadãos. Pautadas por uma ortodoxia moralista burguesa, que contrapõe o mérito ao direito e a autorresponsabilização individual à proteção social pública, tais políticas — a despeito de se manter contraditórias e, por isso, passíveis de reversões — têm apenado a quem mais delas precisam — os cidadãos que vivem do seu trabalho - e privilegiado os interesses do capital. É o que será discutido a seguir.

\section{Tendências regressivas da política social sob a égide do Estado penal: da idade de ouro à idade de bronze}

Se entre os anos 1945 e 1975 as políticas sociais das chamadas democracias ocidentais conheceram uma "fase de ouro", que lhes permitiu realizar, mediante intervenções públicas, melhorias nas condições de vida e de trabalho de considerável parcela da população, a partir dos anos 1980 tais políticas ingressaram em outra fase: a de "prata" (Moreno, 2012). Esta começou a romper com a responsabilidade democrática da "idade de ouro" anterior, que prestigiava os direitos humanos.

O primeiro grande passo nessa direção foi o desmonte do amplo consenso interclassista, estabelecido após a Segunda Guerra Mundial, em torno da proteção social pública. E isso ocorreu no contexto da crise capitalista do final dos anos 1970 que, a par de produzir o esgotamento do modelo econômico keynesiano-fordista, sustentáculo do Estado social, expandiu a ideologia 
neoliberal estadunidense para a Europa e demais países desenvolvidos, a começar pela Grã-Bretanha. Tal expansão exigiu a adoção de políticas econômicas e sociais ortodoxas, que pregavam: cortes nos gastos sociais, retração da intervenção pública, ênfase no controle da inflação, forte disciplina financeira e enfraquecimento dos movimentos e organizações trabalhistas (Moreno, 2012, p. 20).

Embora essas políticas não tenham se disseminado uniformemente e nem rendido ativos políticos homogêneos aos diferentes governos nacionais que as promoveram, é fato que, onde quer que elas tenham se realizado, os direitos humanos perderam força. Coerentemente, "uma inédita aversão à intervenção estatal" (Moreno, 2012, p. 21) foi se robustecendo, no mesmo passo em que uma fé fundamentalista no trabalho assalariado e na capacidade do mercado (inclusive o financeiro) de gerir a vida econômica e social se transformou em dogma.

Em vista disso, as teses neoliberais, enaltecedoras "da eficiência, da criatividade e da inovação mercantis" (Idem) ressuscitaram antigas doutrinas econômicas, como as de Schumpeter, que postulava, entre outras orientações, a destruição criadora e a emergência de empresários audaciosos (Jessop, 2013). Além do mais, a fé fundamentalista e suas teses, consolidadas no chamado Consenso de Washington, de 1989, fortaleceram a convicção neoliberal de substituir o keynesianismo pelo monetarismo.

Foi sob a batuta monetarista que a "idade de prata" da política social ganhou consistência e, conforme Moreno (2012), sucumbiu aos ditames do mercado. Desde então, tal política convive com o desmonte gradativo dos direitos humanos, principalmente os sociais; a privatização de bens e serviços sociais; o enaltecimento do trabalho assalariado, remunerado ou autorrentável, como o meio mais digno e eficaz de enfrentamento da pobreza; e a sua focalização na pobreza extrema, sob a mais estreita forma de "alívio" (relief) assistencial. Paralelamente, verificou-se o esvaziamento da atribuição primordial dessa política, que é a de concretizar direitos sociais, e o culto à meritocracia; isto é, ocorreu a reificação de uma prática que, ao mesmo tempo em que negava ao pobre a proteção social pública, o submetia ao teste seletivo do merecimento, que, a despeito de se considerar imparcial e moralmente defensável, 
pautava-se pelos princípios da hierarquia e da competição. Logo, em vez de direitos, tais políticas passaram a operar mecanismos de triagem entre quem merecia ou não ter as suas necessidades "aliviadas" pelo Estado, sendo que mérito, neste caso, tinha sabor de demérito, visto que o merecedor era tido como fracassado.

Tem-se, assim, uma flagrante sucumbência da política social aos imperativos do mercado, a qual pode ser sucintamente descrita como uma drástica guinada para a extrema-direita das suas características social-democratas, vigentes entre os anos 1945 e 1975. É por isso que se diz que a política social contemporânea, além de se ter tornado "de direita" e se colocado mais a serviço das necessidades do capital do que das necessidades sociais (Gough, 2003), está sendo impedida de concretizar direitos sociais - estes sim uma relevante conquista civilizatória nos limites do capitalismo. E esse fato, evidentemente, constitui a maior tragédia para as parcelas mais desprotegidas da sociedade porque, sem direitos assegurados, elas ficam sem salvaguardas.

Desde então, tornou-se compulsória uma prática moralista de ativar os pobres para o mercado de trabalho, ou para atividades autossustentáveis, por meio das quais poderiam obter renda para sobreviver e "comprar" benefícios e serviços sociais que antes o Estado tinha o dever de distribuir, incondicionalmente.

Cristalizou-se, desse modo e à margem dos direitos de cidadania, o princípio da autorresponsabilização, já referido, o que em outras palavras quer dizer: autonomia econômica dos indivíduos por meio de sua inclusão ativada pelo Estado nos precários circuitos empregatícios disponíveis (Siis, 2012).

Com base nesse princípio - que não é novo e remonta à famigerada Lei dos Pobres inglesa, instituída pelos liberais no século XIX —, reafirma-se a ideologia liberal de que "todos devem ser considerados responsáveis tanto pela sua pobreza quanto pelo seu comportamento" (Sader, 2003, p. 44); e, portanto, a pobreza não deve ser utilizada para desculpar erros ou crimes cometidos pelos seus portadores.

Tal tendência se agravou ainda mais com o passar do tempo. No início dos anos 2000, a legitimação da política social como ação punitiva da pobreza facilitou a sua entrada na chamada "idade de bronze", de acordo com Moreno 
(2012), na trilha do processo de agudização da crise capitalista global e sistêmica, em 2008.

Mas antes de tecer comentários sobre essa última fase de decadência da política social, convém trazer à tona os ataques de filiação pós-moderna que, em consonância com o ideário de uma "nova direita" emergente, foram desferidos contra a pretensão dessa política de ser uma área de conhecimento. Assim, se no seu período de ouro tal política teve algum estofo teórico, agora o seu perfil é outro. Ela vem sendo obrigada a restringir-se a uma ação que, como tudo o que se baseia em dogmas, palavras de ordem e ideias preconcebidas, recusa a teoria como recurso necessário a um processo de conhecimento que transcende o senso comum e especulações intuitivas. Daí a reiteração do entendimento, estrategicamente difundido, de que a teoria, no campo da política social, é um luxo intelectual, e não uma necessidade (Bruyne, Herman e Schoutheete, 1977, p. 101). Ou daí o prevalecimento de posturas acríticas e miméticas, adeptas do pragmatismo pós-moderno, que produzem indagações como essas (Sader, 2003, p. 13): "Para que teoria, se os índices do mercado afirmam o que é e o que pode ser feito; o que vale a pena e o que não adianta; o que é bom, bonito e legítimo?". Ou, então: para que servem as grandes narrações teóricas, típicas da era moderna, se estamos vivendo em outra era, a pós-moderna, que se contenta com o conhecimento de pequeno porte, ou com o que o noticiário da televisão e os colunistas econômicos divulgam? (Sader, 2003; Boron, 2001).

Não admira que, em meio a essas mudanças, e certamente por causa delas, a pobreza, que teima em crescer até nas cidades vitrines do chamado Primeiro Mundo, como Nova York, Londres, Paris, seja considerada um delito ou um símbolo da barbárie terceiro-mundista, que ofende a civilização capitalista. Por isso, a pobreza passou a servir de álibi ao controle punitivo, seja por meio da repressão policial saneadora, seja por meio da educação corretora e adestradora para o trabalho impositivo (o workfare), que vem se tornando a forma privilegiada de "inclusão excludente" (Martins, 1997) na atual idade de bronze da política social.

8. Fusão de neoliberais e neoconservadores. 


\section{Motivos e práticas da atuação crescentemente perversa da política social}

Segundo Sader (2003, p. 41), depois do atentado às torres gêmeas de Nova York, os Estados Unidos, nas suas relações internacionais, sepultaram antigos conceitos políticos como "dissuasão", "contenção", "aliança”, "ajuda internacional", "relações entre Estados fortes e fracos". Em compensação, surgiu não só uma nova linguagem, mas também uma nova filosofia de regulação social, acompanhada de uma crítica radical ao Estado social e de uma firme condenação dos direitos sociais. E isso não só em relação às pessoas pobres, mas também a países e continentes inteiros, terceiro-mundistas.

Acreditando ser missão sua travar uma guerra infinita entre a civilização e a barbárie, e identificando a pobreza com o caldo cultural desta última, nada mais natural do que utilizar a política social e particularmente a assistência como um dentre outros instrumentos estratégicos nessa guerra.

Isso explica a maior ênfase nos projetos correcionais do que sociais; e mais empenho no fomento de medidas que despertem a consciência de cada um acerca de seus atos, do que no resgate social da miséria e do abandono (Sader, 2003) a que muitos condenados pelo sistema estão sujeitos. E, como corolário, tem sido incentivada a substituição do bem-estar como direito (Welfare) pelo bem-estar em troca de trabalho (workfare) que, de regra, se confunde com sacrifícios e expiações de culpas morais.

Esta tem sido a ortodoxia do momento, na qual, como nunca, a relação entre política social e ética capitalista do trabalho se tornou visceral. Acossada por uma feroz competição, a política social tem sido instada a deixar de ser "passiva" para ser "ativa" pela via da indução dos demandantes da proteção social pública para o exercício de atividades econômicas. Assim, ainda que tal transição se apresente como uma espécie de proteção ao desemprego estrutural e massivo que, desde os anos 1970, se tornou um dos maiores fantasmas dos países capitalistas centrais, ela é francamente funcional à política econômica geral. Seus efeitos sobre a legitimidade do trabalho assalariado como fator primaz de produção, de valorização do capital e de reprodução social da força de trabalho são evidentes, assim como se torna clara a importância desses efeitos para o fortalecimento do credo neoliberal de que o mercado de trabalho 
seria o melhor agente de bem-estar dos indivíduos. Afinal, não se pode esquecer que é a exploração do trabalho, por meio do mercado laboral, e não a eficiência pura e simples deste mercado, que garante o crescimento capitalista.

Consequentemente, o direito à proteção contra os abusos do trabalho assalariado tem se esvanecido porque a conquista do trabalho em si, ou como simples meio de obtenção de rendimentos econômicos, tornou-se essencial. Poder trabalhar, em conformidade com a lógica capitalista, inclusive na concepção de setores ditos progressistas, transformou-se no melhor ganho político e maior "direito de cidadania" conquistado pelos que foram obrigados a depender das políticas passivas de bem-estar social (leia-se incondicionais). Essa é a ilusão de corte schumpeteriano, num primeiro momento de predomínio do modelo monetarista de desenvolvimento capitalista, e de corte ricardiano (tributário da economia política clássica) da atual idade de bronze da política social, cujo lema é o bem-estar humano por meio do trabalho remunerado; ou do que foi concebido nos Estados Unidos desde os anos 1970, que é a substituição progressiva e perversa do Welfare pelo workfare.

Embora seja difícil definir o workfare, este pode ser descrito, segundo Gough (2000), como um contraponto à política social incondicional e como direito. Constitui uma política compatível com um tipo de intervenção social requerido por uma economia capitalista internacionalizada, de última geração, preponderantemente baseada no conhecimento e na financeirização (Jessop, 2013). Tais formas de funcionamento econômico tem sido associadas a Schumpeter e a David Ricardo porque, no que se refere ao primeiro, elas privilegiam o conhecimento de ponta, o empreendimento audaz, o empoderamento e a autossuficiência em relação ao Estado. Em vista disso, as pressões estruturais e políticas para desmantelar direitos, reduzir salários e diminuir gastos sociais são enormes, o que induz ao prevalecimento de medidas sociais ativadoras de mecanismos que reforcem a rentabilidade econômica. A privatização e a monetarização dos programas sociais, atualmente em voga, são exemplos eloquentes dessa indução. Mas é a associação das políticas sociais atuais às teorias ricardianas que caracterizam a idade de bronze dessas políticas. Nessa associação - cabe ressaltar com base em Jessop (2013) —, transparece a adequação das políticas sociais à contemporânea forma de acumulação capitalista 
ancorada nas finanças - e não só no domínio do conhecimento. Sendo Ricardo o teórico do comércio internacional e defensor da exploração do fator de produção mais barato e abundante (o trabalho), é nele que a ética capitalista corrente vem se inspirando. E, consequentemente, a ruptura com os direitos sociais (agora chamados apenas de entitlements) tem radicalizado no rebaixamento dos salários, na flexibilidade do mercado e na diminuição dos custos sociais do Estado. Trata-se, em suma, do aprofundamento mais acentuado dos mandamentos neoliberais do livre mercado e da competitividade privada, que se traduzem nas seguintes tendências de extração ricardiana: desregulação, tanto do mercado para liberar a competição, quanto dos ordenamentos legais e do controle dos Estados nacionais; privatização do setor público; residualização e focalização da política social com o objetivo de criar condições favoráveis à generalização de uma cultura mercantilista; internacionalização da economia interna para evitar incompatibilidades com os fluxos econômicos mundiais, precaução contra pressões competitivas e, supostamente, propiciar o aprendizado de boas práticas comerciais e financeiras; e estímulo ao consumismo.

É nessa conjuntura que as políticas sociais, especialmente a assistência, tornaram-se reféns da prédica da ativação e do workfare. E, como tal, se converteram em estratégias complementares de exploração econômica ricardiana do trabalho, considerado este na sua mais bitolada expressão de insumo-chave ou mero fator de produção a serviço da reprodução do capital (Jessop, 2013).

Eis por que o primeiro compromisso da política de assistência social, transvertida em alívio, passou a ser com o trabalho (seja ele qual for), e não com o atendimento de legítimas necessidades do trabalhador; e, consequentemente, ela não mais funciona como um um colchão de segurança capaz de impedir que as pessoas pobres se afundem na miséria. Ademais, o workfare transforma a assistência social num trampolim que serve apenas para lançar o pobre para fora da sua órbita em direção ao mundo do mercado, onde o trabalho é desprotegido, precário e flexível. Em alguns casos, o workfare prevê educação e treinamento para tornar laboriosos os beneficiários da assistência social, mas esse expediente faz parte do processo de ativação para mercado de trabalho. 
Nos Estados Unidos, onde o workfare foi concebido, ele tem relação direta com o conceito de subclasse (underclasses), para identificar desvios de comportamento ou uma cultura da dependência específica dos pobres, enquanto na Europa, o workfare tem como referência o conceito de exclusão social (Barbier, 2008). Mas em ambas as concepções percebe-se que, a despeito de algumas diferenciações, eles se distanciam da tradição de análise crítica do sistema que produz a pobreza. A esse respeito, Gough (2000) assinala que tais conceitos expressam um evidente afastamento da análise de tradição marxista, que se centra na categoria classe social; e, para ressaltar a estreita identificação funcionalista desses conceitos, de raiz durkheimiana, Gough lembra que nem o mesmo a categoria status, tributária de Max Weber, é levada em conta. São as categorias anomia, integração, solidariedade, tomadas de empréstimo de Émile Durkheim, que estão em alta.

\section{As desventuras dos direitos humanos}

As implicações das mudanças regressivas das políticas sociais para os direitos humanos têm sido desastrosas e bem conhecidas por aqueles que conseguem enxergar para além da aparência. Todavia, vale listar os principais óbices que essas mudanças vêm impondo a esses direitos nas suas três dimensões: civil, política e social (incluindo-se na dimensão social os chamados direitos difusos).

Começando pelos direitos sociais, cabe ressaltar que, sob o influxo da globalização neoliberal, pós-moderna e "pelo alto", como denomina Otávio Ianni (2004), e das aceleradas inovações tecnológicas que requerem menor quantidade de mão de obra - a despeito da ênfase nas políticas de ativação para o trabalho - 2/3 da população mundial continuam drasticamente atingidos pelo desemprego e insegurança social. Isso quer dizer que apenas $1 / 3$ dos habitantes do planeta foi, e está sendo, contemplado pelos benefícios dessa globalização ou pela oferta de bens, serviços, conhecimentos e informações que ela propicia via mercado - mas sem que esse 1/3 esteja livre da possibilidade de marginalização. Isto porque a busca obsessiva de eficiência 
e lucratividade neoliberal, por meio de feroz competitividade, só faz aumentar os números dos descartáveis. E, nesse processo, os pobres, seja de que lugar for, são, pela sua própria condição de classe, irremediavelmente tragados pelo chamado "darwinismo social", isto é, pela atitude expressa no ditado popular de que "quem for pobre que se quebre", ou aos vencedores o apoio e aos perdedores o extermínio.

Diante dessa tendência, a política social deixou de ser universal para se tornar focalizada na indigência, com toda gama de atentados aos direitos sociais que essa orientação provoca. Nessas circunstâncias, ocorre o seguinte círculo vicioso: o desmonte dos direitos sociais tem como consequência a quebra do protagonismo do Estado na provisão e na garantia da política social, ficando essa provisão por conta do mercado e das organizações da sociedade civil, que não têm poderes para garantir direitos. Mas isso, como diz Alves (2005), longe de produzir sentimentos de solidariedade, gera divisões.

Em sociedades em que predominam abismos sociais e em que o Estado não está mais incumbido de implementar políticas redistributivas e instituir princípios de justiça social, "as classes abastadas se isolam em sistemas de segurança privada" (Alves, 2005, p. 27); e a população cobra dos legisladores diminuição da idade penal de adolescentes em conflito com a lei e penas aumentadas para os crimes comuns, aprofundando intolerâncias sociais preexistentes. Com isso, agridem-se, também os direitos civis.

No Brasil os direitos civis possuem uma história notória de violações. Primeiro, porque eles não funcionam nas ditaduras, e o país já experimentou dois longos períodos de regime ditatorial cujas marcas ainda estão presentes. Nestes casos, a liberdade de ir e vir, de expressão, de imprensa, de organização, de pensamento e de acesso a justiça, é cerceada. Segundo, porque quando essas liberdades são restabelecidas, durante os períodos denominados de redemocratização, a população não mais acredita nas instituições ou tem medo delas. Na última e atual experiência de redemocratização do país, a Constituição federal, promulgada em 1988, resgatou os direitos civis e inovou ao criar outros direitos, como o de habeas data, com base no qual "qualquer pessoa pode exigir do governo o acesso a informações sobre si, existentes nos registros públicos, mesmo as de caráter confidencial" (Carvalho, 2001, 
p. 209); e o mandado de injunção, "pelo qual se pode recorrer à Justiça para exigir o cumprimento de dispositivos constitucionais ainda não regulamentados" (Idem).

Além disso, a referida Carta Magna definiu o racismo e a tortura como crimes inafiançáveis e previu a defesa do consumidor. Foi nesse contexto que também foram criados o Programa Nacional dos Direitos Humanos e os Juizados Especiais de pequenas causas cíveis e criminais, para tornar a justiça mais acessível (Carvalho, 2001). Isso significou inovações legais e institucionais importantes, mas que, na prática, encontram severas limitações. A falta de garantias desses direitos no que concerne à segurança individual, à integridade física e ao acesso à justiça responde pela grande abstinência no uso desses recursos legais, seja porque o interessado não quer contato com a polícia, seja porque a justiça é lenta, cara e seletiva. Poucos são os crimes de homicídio verdadeiramente investigados, principalmente se a vítima for pobre ou anônima.

Por outro lado, a descrença no sistema político e nos políticos em si tem desestimulado o exercício dos direitos políticos por parte de grande parcela da população. Assim, apesar de a Constituição federal de 1988 ter inovado também neste âmbito, facultando o voto ao analfabeto e ao jovem a partir dos dezesseis anos de idade, muitos eleitores quando não votam por obrigação, quase sempre votam contra alguém ou por protesto (Carvalho, 2001). Com isso, agridem-se os direitos políticos conquistados a duras penas pelos movimentos democráticos e, correlativamente, agridem-se os demais tipos de direitos.

Recentemente, ganharam visibilidade os chamados direitos difusos, que, para vários analistas, são extensões dos direitos sociais num mundo globalizado e tecnologicamente avançado (Pisón, 1998). Tais direitos refletem ainda as novas realidades que afetam o planeta e as transformações globais, requerendo solidariedades e entendimentos entre os seres humanos, como: o direito à paz, ao meio ambiente saudável, à autodeterminação dos povos, à preservação cultural da humanidade. Estes são direitos que interpelam o individualismo neoliberal e as fragmentações pós-modernas, ao tempo em que desafiam governos e sociedades a encontrarem saídas supranacionais, mesmo que regionalizadas, para o seu enfrentamento. 
É nesse ambiente repleto de contradições que a política social se encontra e precisa voltar a estabelecer vínculos orgânicos com a cidadania para que inclusive se justifique como social. Mas para que isso aconteça faz-se necessária a construção de um projeto contra-hegemônico pelas forças sociais que acreditam ser possível construir outro mundo e que nem tudo está perdido.

\section{Ponderações finais}

Um sintoma de que nem tudo está perdido no campo dos direitos e, portanto, desperta esperanças, é o fato, assinalado por Alves, de o discurso dos direitos humanos permanecer vivo e cada vez mais extenso e conhecido. No curso de seus cinquenta e poucos anos de existência, diz ele, esses direitos ganharam aperfeiçoamentos em meio a velhas e novas violações. Inicialmente declarados como direitos do "homem", passaram a se denominar direitos "humanos" para indicar que também as mulheres estavam contempladas. A palavra "universal", que compõe seu título original, ganhou, em 1993, foro de conceito quando, na Conferência de Viena, tais direitos tiveram como apoiadores "representantes de todas as grandes culturas, religiões e sistemas sociopolíticos, com delegações de todos os países de um mundo já praticamente sem colônias" (2005, p. 25).

Disso se conclui que os direitos humanos declarados universalmente e apoiados extensivamente por culturas variadas não perderem prestígio. $\mathrm{O}$ problema é a sua aplicação como um recurso progressista a serviço dos desprovidos de bens materiais e de poder. Este é o desafio do presente que interpela o futuro e compromete todos. E mais: exige que se desmitifique a matriz das desventuras desses direitos: os Estados Unidos legitimado como baluarte mundial da democracia e da paz social.

Para tanto é preciso ter claro que este é, pelo contrário, um país de profundas incoerências e mistificações. É um país que se apresenta como o paladino da paz, mas que foi o que mais guerreou, que se coloca em uma luta antinuclear, mas obsta planos de países que querem apenas ampliar a sua capacidade energética. Além disso, foi o único país que realmente fez uso desses explosivos 
(em duas ocasiões), dizimando centenas de milhares de vidas inocentes, sob o ingênuo (para dizer o mínimo) pretexto de que seria para poupar a vida de soldados americanos e japoneses. Um país que historicamente apoiou e ainda apoia regimes autoritários. Uma nação que iniciou uma guerra "permanente" e "infinita" ao terror, quando foi, e ainda é, a que mais praticou e pratica atos globais de terrorismo.

Enfim, pode-se dizer que o regime de Estado-padrão dos Estados Unidos, desde a Primeira Guerra Mundial, é o do warfare - um constante estado de conflitos e guerras ao redor do mundo, como princípio básico de manutenção do seu modo capitalista de produção, assentado em um colossal complexo industrial-militar. Sobre essa sua característica particular repousa outra contradição fundamental, que é o da não intervenção estatal: os Estados Unidos são um país que sempre pregou a não intervenção do Estado em assuntos pertinentes ao mercado. Entretanto, o esforço e o dinheiro empregados pelos seus governos no fortalecimento do seu modelo capitalista causaria acanhamento ao mais totalitário dos Estados.

Trata-se, na verdade, de um país (os Estados Unidos) capaz de, literalmente, matar para conseguir manter os patamares mínimos de lucratividade de sua indústria. É um país que erigiu, como já salientado, o maior complexo industrial-militar que o mundo já viu, composto de uma formidável rede de empresas, indústrias militares e de inteligência, que existem para salvaguardar os interesses de suas megacorporações e de seus negócios. Na cabeça desse enorme "polvo", com seus tentáculos espalhados pelo globo, estão os principais nomes do sistema financeiro, midiático, industrial e energético estadunidense. E o principal financiador e "chanceler" desse intrincado sistema é ninguém menos do que o próprio Estado, mesmo que a custa de um colossal endividamento público e do desmonte dos direitos de cidadania em larga escala.

Recebido em 8/5/2014 - Aprovado em 2/6/2014 


\section{Referências bibliográficas}

ACANDA, Jorge Luis. Sociedade civil e hegemonia. Rio de Janeiro: UFRJ, 2006.

ALVES, J. A. Lindgren. Os direitos humanos na pós-modernidade. São Paulo: Perspectiva, 2005.

BARBIER, Jean-Claude. L'activacition de la protection social: existe-t-il um modele français? In: GUILLEMARD, Anne-Marie (Org.). Où va la protection social? Paris: PUF, 2008.

BORON, Atílio. A coruja de Minerva: mercado contra democracia no capitalismo contemporâneo. Petrópolis: Vozes, 2001.

BRUYNE, Paul de; HERMAN, Jacques; SCHOUTHEETE, Marc de. Dinâmica da pesquisa em Ciências Sociais. Rio de Janeiro: Francisco Alves, 1977.

CARVALHO, José Murilo. Cidadania no Brasil: o longo caminho. Rio de Janeiro: Civilização Brasileira, 2001.

CHOMSKY, Noam. O que o Tio Sam realmente quer. Brasília: Ed. da UnB, 1999.

DEAN, Hartley. The ethics of welfare-to-workfare. Research Online. Policy and politics, Londres, Poticy Press, v. 35, n. 4, p. 573-590, 2007.

DEPARTAMENTO DE ESTADO DOS ESTADOS UNIDOS. EUA reiteram compromisso de acabar com a fome e a pobreza. Disponível em: $<\mathrm{http}$ //www.livrecomercio. embaixada-americana.org.br/?action=artigo\&idartigo=674>. Acesso em: 28 abr. 2014. GOUGH, Ian. Capital global, necessidades básicas y políticas sociales. Madri/Buenos Aires: Miño y Dávila, 2003.

. From welfare to workfare. Conference on politics and instruments of fighting against poverty in European Community: The guarantee of minimum income. Almansil, Algarve, Febr. $1^{\text {st }}$ and $2^{\text {nd }}, 2000$.

HARVEY, David. O novo imperialismo. 2. ed. São Paulo: Loyola, 2005.

IANNI, Otávio. Capitalismo, violência e terrorismo. Rio de Janeiro: Civilização Brasileira, 2004.

JESSOP, Bob. Política social, Estado e "sociedade". Ser Social, revista do Programa de Pós-Graduação em Política Social da Universidade de Brasília, Brasília, v. 15, n. 33, jul./dez. 2013. 
JUDT, Tony. Pós-Guerra: uma história da Europa desde 1945. Rio de Janeiro: Objetiva, 2008.

MARTINS, José de Souza. Exclusão social e a nova desigualdade. São Paulo: Paulus, 1997.

MÉSZÁROS, István. Crise estrutural do capital. São Paulo: Boitempo, 2009.

MITCHELL, Peter R.; SCHOEFFEL, John (Orgs.). Para entender o poder: o melhor de Noam Chomsky. Rio de Janeiro: Bertrand Brasil, 2005.

MORENO, Luis. La Europa asocial. Crisis y Estado del Bienestar. Caminamos hacia un individualismo posesivo? Barcelona: Península, 2012.

PEREIRA-PEREIRA, Potyara A. Do Estado social ao Estado antissocial. In:

et al. (Orgs.). Política social, trabalho e democracia em questão. Brasília: Universidade de Brasília, Programa de Pós-Graduação em Política Social, Departamento de Serviço Social, 2009.

PISÓN, José Martinez de. Politicas de bienestar: um estúdio sobre los derechos sociales. Madri: Tecnos, 1998.

RAMONET, Ignacio. Geopolítica do caos. Petrópolis: Vozes, 1998.

RELATÓRIO ANUAL DA ANISTIA INTERNACIONAL. UOL Notícias. São Paulo, 28 maio 2009.

SADER, E. A vingança da história. São Paulo: Boitempo, 2003.

Crise hegemônica na América Latina. Em Pauta, revista da Faculdade de Serviço Social da Universidade do Estado do Rio de Janeiro, n. 19, 2007.

SIIS. Centro de Documentacíón y Estudios. Bilbao: Servicio Central de Publicación del Gobierno Vasco, 2012.

WACQUANT, Löic. West Side Story: um bairro de alta insegurança em Chicago. Margem Esquerda, São Paulo, n. 8, 2006. 